\title{
LA EXTENSIÓN DEL SENTIMIENTO DE INSEGURIDAD ENAMÉRICA LATINA: RELATOS, ACCIONES Y POLÍTICAS EN EL CASO ARGENTINO
}

\author{
Gabriel Kessler
}

RESUMO

La preocupación por el delito se ha extendido en toda América Latina. Además de presentar los resultados de una investigación realizada en la Argentina con métodos cuantitativos y cualitativos, este artículo intenta contribuir a la comparación con procesos similares en otros países de la región. La idea central es que la generalización del sentimiento de inseguridad produce consecuencias en el plano de los imaginarios, lo que se llamará relatos de la inseguridad y de las prácticas sociales, la gestión de la inseguridad. Asimismo, se modifica la asociación exclusiva entre temor y autoritarismo, forjadas cuando la inseguridad era inquietud de una minoría. Una serie de paradojas centrales en este campo de estudio en el mundo anglosajón, esto es, el enigma de porqué los grupos menos victimizados son en apariencias los más temerosos, se revisan para el caso argentino.

PALAVRAS-CHAVE: delito; temor; Argentina.

\section{INTRODUCCIÓN}

En el 2008 la delincuencia fue considerada como el principal problema por los latinoamericanos (LATINOBARÓMETRO, 2008, p. 25) ${ }^{1}$. Tal hecho no resulta tan sorprendente si se considera que con sólo el $14 \%$ de la población mundial, menos del $4 \%$ de las armas mundiales en manos civiles, la región concentra el $40 \%$ de los homicidios cometidos en el globo con armas de fuego (KARP, 2009, p. 15). A pesar de la varianza en las cifras de delitos entre los países ${ }^{2}$, los habitantes de distintas naciones coincidían en priorizar el tema. La preocupación se duplicó entre 2003 y 2007 (DAMMERT, ALDA \& RUIZ, 2008 , p. 21) y ha cobrado relevancia aun allí don-

1 En 1995, primer año de esta encuesta regional anual, sólo el $5 \%$ de los entrevistados de 18 países ubicaban a la delincuencia como principal problema del país, en el 2008 era un $17 \%$ y por primera superaba al desempleo. Se trata de resultados generales, por lo cual hay diferencias entre los países: mientras el delito ocupaban un primer lugar en Venezuela, Nicaragua y México, su lugar era menos relevante en otras naciones.

2 Las tasas medias de homicidios sobre 100000 habitantes en el decenio 1995-2005 muestran en un extremo a El Salvador con 48,8, Colombia con 43.8 y en el otro a Chile 5,4 y Uruguay con 5,6 (WAISELFISZ, 2008, p. 35). de las tasas de delito son comparativamente bajas, como lo muestra la centralidad de la cuestión en las últimas elecciones presidenciales realizadas entre fines del 2009 y principios del 2010 en Costa Rica, Chile y Uruguay ${ }^{3}$.

$\mathrm{Si}$ en cuanto a los homicidios las diferencias nacionales son muy importantes, las encuestas de las grandes urbes de la región convergen en establecer entre un 30 o $40 \%$ de población victimizada en un año (TUDELA, 2006), más del doble del 15\% del promedio en Europa Occidental (VAN DIJK et alii, 2005). La expectativa de sufrir un hecho, a su vez, acompaña estas diferencias intercontinentales: el $25 \%$ de los que expresaban su temor en este estudio europeo empalidece frente al $60 \%$ o $70 \%$ que lo declaran en nuestras encuestas (TUDELA, 2006). Tasas de delito y temor conservan una lógica de las proporciones: la segunda suele ser el doble o más de la primera. La "presión ecológica" (ROCHE, 1998) lo explica:

\footnotetext{
3 Laura Chinchillla, electa presidente de Costa Rica, señaló a la lucha contra crimen organizado como el principal problema del país (cf. CHINCILLA, 2009). En Chile, una de las principales prioridades de S. Piñera es "ganarle la batalla a la delincuencia" para lo cual propone medidas tan controversiales como una red de 50000 informantes de la policía en la población (cf. WERTH, 2010).
} 
cuanto más personas victimizadas hay en una ciudad o en una zona, más información sobre estos hechos circula y se intensifica la preocupación, más allá de haber sufrido o no un delito personalmente.

Proyectada sobre el plano espacial, entonces, se restituye una lógica entre tasas de delito y temor, no obstante lo cual, el sentimiento de inseguridad es un hecho social diferenciado del crimen, con su dinámica y consecuencias sociales específicas. Exponer esto es el objetivo del presente artículo, basado en una investigación realizada en Argentina ${ }^{4}$ donde la preocupación es muy intensa: se ha ubicado en segundo lugar mundial entre 42 países en una investigación del 2006, sólo superada por África del Sur (ESTUDIO AC NIELSEN, 2006) $)^{5}$. Mientras que encuestas de mediados de los años 1980 registraban alrededor de un $20 \%$ de población preocupada por el tema y un $40 \%$ a fines del decenio siguiente, la inquietud alcanza a casi un $80 \%$ de los entrevistados en el $2009^{6}$. Poco importa que las tasas de homicidios sean menores a las de gran parte de los países de la región, han sobrepasado su media histórica y el delito en general ha aumentado un $250 \%$ en las últimas dos décadas ${ }^{7}$. Así las cosas, la sociedad sufre una dislocación de su relación tradicional con el delito, sin detectarse una mayor aceptabilidad de las nuevas tasas. Muy por el contrario, el descontento es creciente, tanto como el descreimiento de un mejoramiento futuro, tal como todas las encuestas de los últimos años lo muestran.

En virtud de la centralidad regional del tema, el artículo desarrollará aquellos tópicos que pudieran ser más fructíferos para la comparación con otros países. La idea central es que la extensión social del sentimiento de inseguridad produce

\footnotetext{
4 Este artículos se basa en hallazgos presentados más extensamente en Kessler (2009).

5 La preocupación por el delito era del 18\% en América Latina, $24 \%$ en la Argentina y $7 \%$ en el resto de los países.

6 Datos extraídos del banco de datos de Ipsos-Mora y Araujo y resultan de adicionar las siguientes preguntas: ¿cuál es el problema más grave del país?, ¿en segundo lugar?, ¿en tercer lugar?

${ }^{7}$ La tasa de homicidios dolosos era de cinco sobre 100000 en 1984, llegando a casi el nueve en 2003 para luego conocer una reversión hasta un siete. Los delitos contra la propiedad pasan de 1500 sobre 100000 en 1984 al 3500 en 2003 (KOSOVSKY, 2007).
}

consecuencias específicas en el plano de los imaginarios y de las prácticas sociales. La generalización de la inquietud también cuestiona consensos fundados en momentos donde la preocupación era más restringida. ¿Qué procesos alimenta el sentimiento de inseguridad al extenderse? El acuerdo acerca de que se trata de un problema público cualitativamente diferente de lo habitual en el pasado plantea una serie de interrogantes: sobre las causas, los riesgos personales y las soluciones necesarias. Las respuestas son las piezas que conforman los relatos sociales sobre la inseguridad. Tal definición de la realidad sugiere qué emociones son lógicas sentir y se proyecta al terreno de la acción, sobre las precauciones obligadas, que llamaremos gestión de la inseguridad. En cuanto a los consensos trastocados, se modifica el clásico vínculo entre temor y autoritarismo. Finalmente, las paradojas de la inseguridad, esto es, el enigma de porqué los grupos en apariencia menos victimizados son los más temerosos, en torno a cuya elucidación se organizó parte de este campo de estudio, serán sometidas a revisión con el recurso de la perspectiva cualitativa.

En sus sucesivas secciones este artículo transita por las cuestiones señaladas. En la primera parte se presentan precisiones conceptuales; a continuación se revisa la dimensión política, seguidamente los relatos, luego las acciones y en fin, las paradojas y la gestión de la inseguridad. Cerraremos el trabajo planteando interrogantes sobre los puntos en común y las diferencias entre los países de la región. Las reflexiones se basan en una investigación desarrollada con métodos cuantitativos, cualitativos y archivos de prensa en diferentes etapas entre el 2004 y principios del $2009^{8}$. Centrada sobre todo en la ciudad de Buenos

\footnotetext{
8 El trabajo cualitativo fue realizado en distintas fases. En una primera se realizaron 70 entrevistas entre el 2004 y 2006 en el área metropolitana de Buenos Aires. Los criterios de selección respondían a variables socioeconómicas, ocupacionales, de sexo, edad y experiencias de victimización. En segundo lugar se efectuaron 30 entrevistas en la Ciudad de Córdoba que cuenta con un millón y medio de habitantes, Posadas con 300 000, capital de la provincia de Misiones, en el Noreste del país, un pueblo de 1300 habitantes y una ciudad de 10000 cercanos entre sí, ambos de la Provincia de Buenos Aires. En 2006-2007 se co-dirigió un trabajo en un Conjunto Habitacional del conurbano bonaerense altamente presente en los medios de comunicación en relación con la problemática de inseguridad.
} 
Aires, se ha realizado trabajo de campo también en otros centros urbanos.

\section{DEL MIEDO AL CRIMEN AL SENTIMIENTO DE INSEGURIDAD}

El "miedo al crimen" surge como campo de estudios en Estados Unidos a mediados de la década del 1960. Fue un resultado inesperado de investigaciones que buscando constatar un denunciado aumento del delito en el momento de las luchas por los derechos civiles, no corroboraron tal incremento pero sí del temor ${ }^{9}$. Tampoco establecieron una relación significativa entre haber sido víctima de un crimen y el miedo, aunque sí entre éste y la ansiedad frente a la integración racial incipiente. Desde los primeros estudios el miedo al delito ha exhibido una autonomía relativa: suele aumentar al incrementarse la victimización pero una vez instalado como problema social, ya no disminuye aunque las tasas de delito lo hagan. No guardaría relación con las probabilidades de sufrir un hecho de cada categoría social. El mayor temor de mujeres y adultos mayores a pesar de ser menos vulnerables al delito, así como el poco impacto de la victimización, son las paradojas que se ha intentado explicar.

Su marca de origen perdurable será esta relación conflictiva con el delito: la sospecha de ser el nexo convergente de otras inquietudes, a menudo de las peores pasiones públicas; un objeto de emoción diferenciado de sus causas, para retomar la fórmula clásica de D. Hume (2002), Por ello, mientras que la criminología ha intentado encontrar la lógica de las paradojas mencionadas focalizándose en la relación entre ambos hechos, otras corrientes de estudio lo han vinculado más a una hipersensibilidad posmoderna al riesgo (GIDDENS, 1991), a la frustración de una promesa securitaria junto a la erosión de las

Entre 2008 y 2009 se hicieron grupos focales con jóvenes. Se utilizaron datos cuantitativos de distintas investigaciones y se participó en 2007 en el diseño y análisis de una encuesta de victimización de 25000 casos realizado en la Ciudad de Buenos Aires por el gobierno municipal y la Universidad de San Andrés.

9 El miedo al crimen ("fear of crime") es hoy un subcampo de la criminología con un desarrollo considerable. Para un estado del arte con los principales hallazgos, ver Hale (1996). Ditton y Farrall (2000) es una compilación de artículos paradigmáticos. garantías ofrecidas por el Estado de Bienestar (CASTEL, 2003; LAGRANGE, 2003). En América Latina, por su lado, se lo vinculó a las ansiedades propias de una modernización urbana periférica (LECHNER, 1990; REGUILLO, 2000), a la herencia de las dictaduras militares (KOONINGS \& KRUIJT, 1999), aunque también una incipiente literatura ha intentando explicar su relación con el delito (CALDEIRA, 2001; DAMMERT \& ARIAS, 2007; BERGMAN \& FLOM 2008; KESSLER, 2009).

La criminología define al miedo al crimen como "una respuesta emocional de temor o de ansiedad frente al crimen o a símbolos que la persona asocia con el crimen" (FERRARO, 1995, p. 4). Preferimos en cambio la idea de sentimiento de inseguridad, puesto que si las referencias al temor no dejan de ocupar un lugar central, incluye otras emociones suscitadas, como la ira, la indignación o la impotencia y comprende también las preocupaciones políticas, los relatos sobre sus causas y las acciones que conformarán la gestión de la inseguridad. Por otro lado, mientras que esta noción intenta abarcar un fenómeno multidimensional, la criminología se ha abocado a encontrar un indicador que sintetice la esencia del problema ${ }^{10}$. Ahora bien, ¿qué es la inseguridad, según los entrevistados argentinos? No se refiere a todos los delitos violentos, se excluye los que se vinculan con el crimen organizado que sólo afectarían a sus copartícipes y puede incluir acciones que no suponen la infracción de la ley, como el temor que ocasiona en algunos, la presencia de grupos de jóvenes en la calle sin violar norma alguna. Su rasgo particular es la aleatoriedad del peligro. Podría definirse como toda amenaza a la integridad física, más que a los bienes, que

\footnotetext{
10 Las primeras preguntas indagaban sobre una sensación general de inseguridad en el entorno, poco específica en relación con el crimen ("Se siente ud. muy seguro/seguro/ un poco inseguro/nada seguro caminando casa sólo de noche por su barrio"). Se sugirió entonces diferenciar entre una preocupación por el tema como problema público, una dimensión cognitiva de percepción de probabilidad de ser víctima y el temor (FERRARO \& LAGRANGE, 1987). Los estudios actuales suelen interrogar sobre el miedo personal a delitos específicos así como en el caso de la encuesta de victimización británica, la frecuencia en que se experimenta preocupación ("worry"), obteniéndose con ambas innovaciones valores menores que al responderse por una sensación de inseguridad genérica (JACKSON, 2005).
} 
parecería poder abatirse sobre cualquiera. Esto explica porque en una jerarquía de delitos temidos, uno poco frecuente y al mismo tiempo más cercano a la aleatoriedad ("que te ataquen en la calle sin motivo") haya ocupado el segundo lugar entre los temores de los habitantes de Buenos Aires encuestados en el 2007. La aleatoriedad se fundamenta en la percepción del incremento de hechos y se proyecta tanto en el espacio como en la pluralidad de figuras de lo temible.

En relación a lo primero, una de sus facetas es la deslocalización del peligro: el fin de la división entre zonas seguras e inseguras bien definidas. Cuando se siente que la amenaza ha sobrepasado sus fronteras tradicionales y puede penetrar en cualquier territorio, se retroalimenta la sensación de inseguridad. Esto constituía una diferencia entre nuestros dos grandes centros urbanos, Buenos Aires y Córdoba respecto de Posadas y las dos localidades más pequeñas, donde el delito seguía asociada a determinadas zonas. Es posible que la centralidad de la figura de un delito anómico, individualizado, producto de la crisis social, diferente a la imagen de las bandas o del crimen organizado con un territorio bajo su control, contribuya a la deslocalización del delito, a pesar de que la distribución del delito no es en verdad aleatoria, sino que está en el caso de Buenos Aires mucho más presente en las zonas de menores ingresos (BERGMAN \& KESSLER, 2009).

En segundo lugar, se produce una desidentificación relativa de las figuras de temor: la percepción de amenaza no se limita sólo a las imágenes más estigmatizadas, como los jóvenes de sectores populares. En efecto, los entrevistados relatan robos de parte de personas "bien vestidas", que "parecía gente de clase media"; en urbanizaciones privadas circulan historias de gente que ha entrado a robar "vestida con traje y corbata, como un nuevo vecino que venía de trabajar", y en comercios de barrios populares, se describen hechos protagonizados por mujeres, algunas con bebés en brazos, o incluso por parejas de ancianos. De este modo, las figuras habituales de estigma y temor siguen siendo compartidas así como hay otras más temibles según el sector social, sexo, grupo de edad y área de residencia. Policía y guardias privados en los lugares de diversión para jóvenes de sectores populares; agresores sexuales, para las mujeres de barrios de los suburbios de Buenos Aires; personas ligadas al poder local capaces de todo tipo de abuso, para los sectores populares del interior; "gente que antes no existía", como limpiavidrios de autos, mendigos o cartoneros, para algunos entrevistados de sectores altos de la ciudad de Buenos Aires, mientras que otros temen a la policía y desconfían de los guardias privados. La deslocalización y la desidentificación no produce la abolición de ciertos estigmas y prejuicios sobre personas y lugares, por el contrario, esta pluralidad de imágenes refuerza la sensación de una amenaza aleatoria y omnipresente.

\section{TEMOR Y POLÍTICA}

Distintos estudios han señalado que el incremento de la sensación de inseguridad afecta la calidad de vida, favorece el apoyo a las políticas más punitivas, contribuye a la deslegitimación de la justicia penal, promueve el consenso en torno a las acciones "por mano propia" y a la difusión del armamentismo (HALE, 1996). En líneas generales, temor y autoritarismo han sido asociados y sin duda, cuando la preocupación afectaba a una parte minoritaria de la población penetraba sobre todo en los sectores más conservadores. Esto cambia necesariamente cuando se extiende, aunque sus consecuencias políticas no son unívocas. Para D. Garland (2005) el incremento del miedo en las clases medias de los Estados Unidos e Inglaterra debilitó desde los años 1970 el sostén que las elites progresistas brindaban a una política penal y judicial más benigna, generando consenso hacia medidas más punitivas. En Francia P. Robert y M.-L. Pottier (1997) advirtieron la persistencia durante dos décadas de un "síndrome conservador-autoritario" que asociaba la preocupación por la seguridad, la xenofobia y el apoyo a la pena de muerte frente al cual hacían las veces de "antídoto" ser de izquierda, tener mayor capital cultural, ser ateo o agnóstico. En un estudio posterior los mismos autores (ROBERT \& POTTIER, 2004) detectaron un nuevo grupo, los "neo-inseguros", cuyos miembros provienen de las categorías antes exorcizados de tal preocupación y para los que la inseguridad se disocia de los otros elementos del síndrome autoritario: están preocupados por el tema pero no son xenófobos ni apoyan la pena de muerte.

El caso argentino se asemejaría más al francés. En la encuesta de la ciudad de Buenos Aires la preocupación por el delito alcanzaba a un $70 \%$ de los entrevistados, pero las medidas para combatir 
la inseguridad que más apoyo tenían eran las sociales: consolidar la educación y luchar contra el desempleo; les seguían las legales: combatir la corrupción policial y hacer que las leyes se cumplan y recién en último lugar se ubicaban las punitivas: castigos más severos y la aplicación de la pena de muerte. A. Otamendi (2009) en el análisis de una encuesta nacional distingue un polo de apoyo a un Estado mínimo, la predilección de medidas punitivas y de solución rápida al delito frente a otro asociado con una definición más amplia del rol del Estado, que apoya medidas sociales como solución al delito y concibe en consecuencia que la solución será más lenta. Como veremos en el próximo apartado al tratar los relatos, la inseguridad se procesa diferentemente según las ideologías previas pero no las deja indemnes.

Tampoco los discursos más autoritarios se mantienen idénticos a los del pasado. En los comienzos del trabajo de campo en el 2004, todavía era posible escuchar que "durante el gobierno militar [1976-1983] había más seguridad”, ya que la represión del Estado estaba (sólo) dirigida a quienes "estaban en algo". En las últimas fases del trabajo la situación era distinta. La reapertura de los juicios contra los militares por crímenes contra la humanidad desde el 2004, y el develamiento de nuevos delitos de la dictadura que para mucha gente no podían asociarse con lo político - sobre todo robos de bebés, pero también secuestros a empresarios y saqueos de bienes fue deconstruyendo la oposición clásicamente reaccionaria: "democracia insegura versus dictadura segura". Los discursos autoritarios se van reorganizándo sobre nuevos ejes. En primer lugar, el paso del tiempo erosiona la dictadura como hito de referencia, en particular en las nuevas generaciones que han nacido en democracia. En tal sentido, en ciertos grupos focales con jóvenes porteños de niveles medio-altos a fines de 2008 observamos que eran sumamente liberales en temas ligados a la diversidad, como las minorías sexuales, religiosas o los grupos estéticos, mientras que eran autoritarios en aquello que se refería al delito, al que asociaban de manera abierta con franjas marginales de sectores populares y hasta con un discurso crítico con los derechos humanos: "no podés hacer nada contra los delincuentes porque te vienen los derechos humanos". El delito marcaba una frontera y se advertía una articulación novedosa entre demanda de libertad individual con las de un orden público con características autoritarias.

El autoritarismo no es un efecto mecánico de la difusión de la inquietud; el cambio más evidente es la intensificación de un tipo de práctica social observada y que, siguiendo a M. Lianos y $\mathrm{M}$. Douglas (2000) llamamos "presunción generalizada de peligrosidad". Se trata del trabajo de decodificación de las eventuales amenazas en todas las interacciones y espacios: intentar reconocerlas por gestos, rasgos o silencios; colocar dispositivos para detectar los peligros y mantenerlos a distancia. Esto retroalimenta una disminución generalizada de la confianza, afecta todos los planos de la vida social, clasificando los lugares entre resguardados o potencialmente peligrosos. La generalización de la sospecha tiene cierta continuidad entre prácticas sociales extendidas con acciones públicas. En el plano microsocial, conlleva formas de elusión preventiva del otro que, más allá de la intención manifiesta de quien cree protegerse, produce una evidente discriminación de aquellos que son evitados en los entrecruzamientos urbanos: "ellos te distinguen, por como te vestis, sos una negra para ellos, cruzan la calle, se cambian de asiento en el tren, como si fueras a robarle y te sentís muy mal" nos decía con amargura una joven de los suburbios de Buenos Aires. En un plano más general, esto ayuda a explicar las escasas reacciones contrarias y hasta el apoyo a formas de control por parte de fuerzas de seguridad de asentamientos precarios y barrios tipificados como peligrosos: "Yo no tengo problema que me revisen cada día, porque no tengo nada que ocultar" afirmaba como una suerte de descargo un vecino de Fuerte Apache, un barrio muy estigmatizado y rodeado por la gendarmería. La mirada propia y ajena está influenciada por la instalación de un dispositivo de control. Así, la presunción de peligrosidad generalizada conlleva un riesgo profundo y subrepticio, porque no se plantea como estigmatizador en la intención pero indudablemente lo es. Por otro lado, no sostiene la impugnación de toda diferencia, sino que puede convivir con la aceptación de formas de diversidad y alteridad, rechazando violentamente las que parezcan potencialmente amenazantes.

\section{LOS RELATOS DE LA INSEGURIDAD}

Declaraciones programáticas y orientaciones para la vida cotidiana se combinan en los relatos de la inseguridad de los entrevistados. Con ellos 
elaboramos una tipología de construcciones discursivas, cada tipo es una de las formas socialmente existentes de responder a las preguntas que circulan entre los especialistas, los medios y la sociedad en general sobre las causas de la situación, a qué y a quién se debe temer, qué puede hacer uno para protegerse y cuáles son las tareas que le corresponderían al Estado ${ }^{11}$. Los relatos surgen en parte para explicar por qué la situación ha dejado de ser como en el pasado y ordenan escalas diferentes. Transitan del plano general al personal, vinculando la definición de la realidad social con la vida cotidiana. Por ello, una determinada gestión de la inseguridad intentará ser coherente con el cuadro trazado de la situación: si el mundo se volvió muy peligroso, más vale limitar las salidas; si no es tan así, con algunas precauciones alcanza. ¿Por qué llamarlos relatos? Si por un lado ofrecen un diagnóstico del problema y de lo que debería hacer el Estado, se aproximan a la concepción de Michel de Certeau (2000, p. 128) en cuanto proponen prácticas del espacio que "organizan los andares" y "hacen el viaje, antes o al mismo tiempo que los pies lo ejecutan". Son entonces una suerte de guía para manejarse en la ciudad: cartografías para decidir trayectorias y recorridos entre los lugares, más orientados al espacio que al tiempo.

Decidimos agruparlas por la intensidad de la preocupación y diferenciamos entre ocho discursos divididos en tres grupos, según ésta sea intensa, intermedia o baja. En las narrativas más securitarias, la inseguridad es un eje central de la vida cotidiana y la visión del mundo. La más autoritaria plantea una complicidad delitosubversión en el poder: se trata de una lectura en clave política, la única que reivindica abiertamente la última Dictadura Militar. El delito actual encarna un capítulo más de la lucha constante entre el Bien y el Mal. El mal es el gobierno de N. Kirchner (2003-2007) y Cristina F. de Kirchner, a quienes se caracterizan conformado por ex-Montoneros (grupo armado de origen peronista de los años 1970), o sea delincuentes, de allí una complicidad íntima con el delito actual, por lo cual no sólo no

11 Se trata de una tipología de "agregación en torno a unidades-núcleo" (DEMAZIÈRE \& DUBAR, 1997). Es el resultado de un proceso inductivo de agrupar los discursos individuales según criterios de similitud entre ellos en virtud de las respuestas a los interrogantes señalados. se los persigue y castiga sino que se los favorece con "leyes blandas y jueces garantistas". "Mi vida gira en torno a la inseguridad" aseguraba una representante del segundo relato que sostiene la alterofobia y el encierro como imperativo de la vida cotidiana, puesto que todo aquello que está más allá del mundo cercano, unido por lazos de sangre o muy íntimos, es peligroso o amenazante, sin que las causas aparezcan muy claras. Es un relato policlasista pero que en cada grupo social se focaliza en alteridades distintas y a menudo, juicios xenófobos contra migrantes de países vecinos. Este grupo extrema las medidas de seguridad comprando todo tipo de dispositivos y restrigiendo los movimientos al máximo.

Los discursos de intensidad media coinciden en que la situación se ha degradado, propugnando precauciones, pero sin que el tema sea el centro de los desvelos cotidianos. En ellas se concentran la mayor cantidad de personas entrevistadas $y$, creemos, la mayoría de la población. El relato de la degradación moral, presente en la clase media baja de Buenos Aires, expresa una ideología de derecha pero sin establecer la relación "gobiernosubversión-delito" antes señalada. El eje es una paulatina declinación político-moral que comenzaría con la reinstauración de la democracia en los años 1980 y que se amplifica con la crisis social de los 1990 llevando a la descomposición familiar, el desorden escolar, el incremento del consumo de droga y, por esa vía, del delito. La narrativa de la crisis social comparte con la anterior el hincapié en el quebranto social de los 1990 pero no la atribución causal a la democracia como tampoco pregona una crisis moral. Brinda explicaciones más estructuralistas, sobre las consecuencias de la pobreza y el desempleo en los jóvenes. Es un relato muy extendido, policlasista, presente en personas de izquierda hasta centro-derecha y coincidente con el discurso sociológico y mediático más difundido sobre el tema.

El relato que pone eje en la inseguridad jurídi$c a$ (noción recurrente en ciertos medios opositores en los últimos años sobre un supuesto avasallamiento del gobierno a las instituciones) tiene un aire de familia con una literatura ensayística que describe una sociedad y un Estado caracterizado por una "anomia boba", según C. Nino (1992), la trasgresión constante de las normas de convivencia social. El comienzo de la inseguridad 
sería el "corralito", la caución de los depósitos bancarios por parte del Estado luego de la crisis del 2001, hecho que marcaría un nuevo hito del desprecio de la ley por parte del Estado, transmitiendo así una "sensación de impunidad hacia abajo". Cierra este grupo una narrativa de jóvenes de sectores populares de Buenos Aires, la estigmatización. Se origina por sentirse entre dos fuegos: por un lado, que pueden ser victimizados en sus barrios tanto como ser considerados ellos mismos delincuentes, por su condición social, edad, formas de vestir y rasgos fenotípicos y por ello, maltratados a menudo cuando salen de sus periferias por la seguridad privada de lugares nocturnos y por la policía, a quienes temen por sobre todo.

En tercer término, los relatos menos securitarios comprenden uno muy frecuente en la clase media "progresista": el cuestionamiento de la inseguridad. Se caracteriza por un interrogante sobre la real magnitud del problema, evaluando la situación respecto de otros países, sospechando de la complicidad de la policía con el crimen, caracterizando a los medios como "sensacionalistas" y muy sensibles al riesgo de asociación entre discurso securitario y autoritarismo. En fin, la última narrativa es la negación del temor. "No conozco el miedo" nos aseguraba una pasadora de juego clandestino, de 60 años, viuda, que vivía sola en un suburbio donde el temor era corriente y en el año que la entrevistamos habían asesinado a tres personas. La negación era el resultado de un fuerte trabajo sobre sí mismos, de "no querer enterarse de nada" para preservarse de las consecuencias subjetivas de la inseguridad.

¿Qué enseñan los relatos presentados? Frente a correspondencias estadísticas entre grado de temor y categoría social, ellos plantean diversidad: un mismo tipo de relato se encuentra en grupos distintos y en cada uno de ellos se registran varios diferentes. La realidad cotidiana tampoco es determinante: en casas contiguas, con una situación local similar, los relatos pueden ser de tonalidades heterogéneas. Diversidad no es contingencia y dos variables parecen influir en la adscripción a un relato determinado. En primer lugar, ideas políticas previas que operan en una atribución causal del problema donde gravitarían de forma diferente factores sociales, morales, políticos o individuales y en segundo, la posición frente a las medidas punitivas. No habría tampoco una relación unívoca entre ambos; relatos con atribuciones causales coincidentes daban lugar a posiciones divergentes, tal como sucedía entre la crisis social y la degradación moral: en ambos casos se atribuye el problema en gran parte a causas sociales, pero en uno hay una oposición a políticas punitivas y en el otro, una aceptación plena.

En segundo lugar, influye también la experiencia de clase, cuyas implicancias presentaremos en el próximo apartado. Ahora bien, como se dijo en páginas anteriores, el sentimiento de inseguridad es en gran medida procesado por la ideología política previa, pero la extensión de la inseguridad puede socavar lo preexistente. En los relatos se observan lo que llamamos "deslizamientos punitivos", signos observados durante el trabajo de campo de un abandono de posiciones más benignas y un paulatino apoyo a medidas más duras. Un primer punto es si los eventuales deslizamientos conllevan cambios de relato o se producen sin abandonarlo. Nos parece que los corrimientos tienden a producirse dentro de algunos relatos; ellos tendrían la estabilidad de las estructuras sociocognitivas, son grillas de lectura persistentes, conformadas con ideas, creencias y juicios morales de larga data. Ciertos relatos conllevan posiciones definidas frente a lo punitivo, otros aceptarían variaciones. La complicidad delito-subversión y la degradación moral son militantemente punitivas, y el relato del estigma, el cuestionamiento y, en general, la crisis social se ubican en el campo opuesto. En la alterofobia es predecible un deslizamiento: si para protegerse hay que apelar a cualquier medio, ¿por qué tener acaso algún miramiento? De igual modo, la negación del temor acepta todo lo que garantizaría el olvido del problema; medidas extremas que prometieran reforzar la protección subjetiva, serían aprobadas sin necesidad de mucha argumentación.

¿En qué relatos parece más posible el corrimiento? La crisis social es el caso más relevante. En principio tiene fuertes anticuerpos contra lo punitivo puesto que la mirada sobre la estructura actúa como atenuante, pero se detectan eventuales movimientos: por la visión de que no hay salida a la situación o por una discontinuidad entre el diagnóstico y la necesidad de respuestas inmediatas, diferenciando por ejemplo entre medidas de coyuntura y otras de índole social pero a largo plazo. Quizás sea también el que mayor corrosión esté sufriendo con el paso del tiempo. 
En efecto, su extensión reposa en parte en una sensación de responsabilidad compartida o al menos de contemporaneidad, en particular por la crisis de los años noventa o la del 2001, una comunidad de experiencia que el paso del tiempo ha ido difuminando. Un proceso comparable se puede dar con la inseguridad jurídica: no hay una postura punitiva, pero la solución es una mejor aplicación de las leyes, propuesta que acepta interpretaciones diversas, en particular la definición de lo se considera a menuda una "aplicación severa". No obstante, ni una ni otra parece aceptar medidas extremas y por ello, más que enfrentar el riesgo de una polarización creciente entre partidarios de acciones punitivas y de no punitivas, lo que avizoramos es el fortalecimiento de un campo intermedio entre ambos, pero que en conjunto incline la sensibilidad pública y el baremo de políticas hacia medidas más punitivas.

\section{LAS PARADOJAS DE LA INSEGURIDAD}

Gran cantidad de investigaciones en las últimas tres décadas han intentado resolver una serie de paradojas: ¿por qué la inquietud es, en apariencia, mayor en ciertos grupos menos victimizados, como mujeres y adultos mayores, mientras que es más bajo en los jóvenes y varones, si ellos son más atacados?, ¿cómo es posible que ser víctima de un delito no implique necesariamente más miedo? Los estudios han puesto en relación el temor de cada grupo con sus tasas de victimización y al develar la debilidad de la correlación, elaboraron hipótesis y teorías de alcance medio a fin de explicar hallazgos a menudo contra intuitivos. Revisar tales paradojas en un contexto de extensión de la inseguridad, como es el caso argentino, incluyendo también clase social y recurriendo a la triangulación entre métodos cualitativos y cuantitativos, será el objeto de este apartado.

No hay en las mediciones internacionales ni en el caso argentino tendencias bien definidas respecto de la clase social ${ }^{12}$, pero a nivel cualitativo encontramos diferencias. Al comparar lo que sucedía en periferias populares consideradas por sus habitantes como peligrosas en relación con

\footnotetext{
12 Los estudios internacionales muestran un poco de mayor temor en los sectores bajos en particular por una mayor vulnerabilidad social, por vivir en zonas menos protegidas y por la dificultad de reponer lo sustraído (SACCO \& GLACKMAN, 1987).
}

zonas céntricas de sectores medios-altos, el eje diferenciador es lo que llamamos "distanciamiento y proximidad". La proximidad en los barrios periféricos es la percepción de mayor cercanía física y social con la amenaza: puede ser el hijo del vecino a quien se conoce desde que era pequeño, los que viven "en la cuadra de los ladrones" o un habitante de un lugar cercano. En contraposición, en las zonas favorecidas el distanciamiento con el delito es social y físico. No es raro escuchar que en la zona ocurren hechos, pero protagonizados por sujetos que no forman parte de la misma comunidad, sino que vienen de otra parte, llegan y se van: el peligro no está instalado, no es constante, y los dispositivos adecuados ayudarían a evitarlo.

A la proximidad espacial se le yuxtapone una historia social compartida. La inseguridad sería una de las secuelas de la alteración de la sociedad local producto del desempleo o la pobreza. La clase media tiene su narrativa de la crisis, y aunque no duda en atribuirle el incremento del delito, no vislumbra tal transformación en su categoría social. A su vez, el distanciamiento social y espacial facilita el emocional: entrevistados de sectores medios nos han confiado: "Yo, la verdad, tomo alguna precaución, pero casi no pienso en el tema". La proximidad influye también en la configuración de la lectura política que se edifica, en general, "de abajo hacia arriba". Abundan los debates locales a partir de casos concretos y se discute sobre la propia comunidad: por qué alguien "se fue torciendo", cuál fue el peso de los factores familiares, de la droga y de la falta de trabajo, si la solución pasa por la presencia policial, la escuela o la religión. El distanciamiento favorece una mirada "de arriba hacia abajo", una explicación por procesos sociales o políticos casi sin referencias individuales. Pero ni la cercanía conlleva de por sí más miramientos ni el distanciamiento posiciones punitivas. La proximidad puede llevar a la condena moral: un argumento recurrente en el relato de la degradación moral era que a pesar de las malas condiciones sociales comunes para todos "mis hijos no roban", o, por el contrario, se encuentran atenuantes, ya que "en el fondo no son malos chicos", como se afirma en el relato de la crisis social. Junto al distanciamiento es más habitual la duda sobre "quién está realmente detrás del delito", la apelación a causas estructurales pero también la posición reaccionaria extrema de considerarlo "una forma actual de subversión". 
La segunda paradoja se refiere al género. Los datos sobre un mayor temor femenino han sido una constante en todos los estudios y países. En cuanto a las cifras, la Argentina no es la excepción. Al examinar los determinantes del temor, luego de la presión ecológica, o sea, vivir en un barrio con más delitos, el género era la variable con mayor peso explicativo (BERGMAN \& KESSLER, 2009). Estos hallazgos, comparables a los de otros países, siguen motivando fuertes debates. La crítica feminista ha sostenido que la irracionalidad no debería ser buscada en las mujeres, sino en la baja tasa de temor de los jóvenes varones cuando su victimización es la más elevada. K. Ferraro (1996) ha interpretado el mayor temor femenino mediante las "variables en sombras". Al preguntar por distintos tipos de delitos, ha encontrado que las mujeres eran más temerosas sólo en aquellos casos donde estaba implícito el riesgo de sufrir un ataque sexual, mientras que en otros el temor era similar en ambos sexos. Hipótesis que se corrobora en el caso de la ciudad de Buenos Aires, donde por ejemplo, el robo en autos sin estar dentro, alcanza igual valor en ambos sexos. Otros trabajos demuestran que las formas de victimización femenina tanto en el espacio público como en el privado están subdeclaradas (SACCO, 1990). Sin embargo, registramos en Buenos Aires menos acciones defensivas, como compra de alarmas, cámaras de vigilancia o rejas entre las mujeres ${ }^{13}$. $\mathrm{Si}$, tal como se ha propuesto desde la psicología, al miedo se debería inferirlo más por acciones que por declaraciones (SLUCKIN, 1979), esta disparidad debe ser tomada en cuenta para revisar los presupuestos sobre los sexos.

La hipótesis derivada del trabajo cualitativo es la siguiente: si se instala la inseguridad como problema público, se autorizaría a los hombres a expresar su preocupación así como a sentir y a expresar el temor. Cierto es que los procesos de socialización construyen estructuras de sentimientos diferenciados por género, pero ellas no son inmutables. Al fin de cuentas, si la situación se ha vuelto insegura, lo "lógico" es sentir temor, emoción que se declara en algún momento de una entrevista de larga duración, aun cuando al responder la encuesta por cuestionario se haya nega-

13 Según la encuesta de 2007 en la ciudad de Buenos Aires, en los hogares habitados sólo por mujeres había un promedio de $51 \%$ unidades domésticas con al menos un dispositivo, mientras que en el promedio general alcanzaba al $61 \%$. do a considerarse temeroso. Ahora bien, la diferencia central radica en la forma de hablar del tema. Con el riesgo de ser esquemático, es más habitual que las mujeres se refieran al miedo como una atributo interno, un rasgo de carácter, parte de una identidad afectiva ("soy miedosa" o "no soy miedosa"). Los hombres raramente lo hacen y tienden a decir que "sienten inseguridad" en determinadas ocasiones y lugares. Ubican un referente exterior peligroso, acotado espacial y temporalmente, para luego afirmar que sienten temor cuando están frente al peligro. El temor, entonces sería una consecuencia de un juicio axiológico y cognitivo: si un lugar, un horario o una persona son a todas luces amenazantes, lo lógico es temerle.

Entre las mujeres, ese supuesto rasgo de carácter se enmarca en una narrativa de identidad afectiva durable: al hablar de la situación actual pueden vincular el temor sentido con otros del pasado. Allí se hacen evidentes marcas de una socialización de género puesto que estos se vinculan en algún momento con los consejos familiares de defensa frente a eventuales abusos o agresiones sexuales. Cabe agregar que si los hombres expresan menos miedo, sus relatos denotan una mayor variedad de sentimientos. Afirman sentir impotencia si no pueden impedir un robo o rabia por lo sustraído. Nuestra hipótesis es que tales sentimientos están relacionados con lo que se espera de un rol masculino, sobre todo un papel defensivo, y afloran entonces ante la imposibilidad de cumplirlos cabalmente.

La victimización es la tercer paradoja planteada, ya que los estudios internacionales no encuentra una correlación con el temor ${ }^{14}$. No es el caso de la ciudad de Buenos Aires, donde es un predictor de mayor expectativa de victimización futura (un $50 \%$ más que en relación con los no victimizados). Otras aristas se desprenden el análisis cualitativo. Haber sido víctima de un delito, en particular violento, opera en la redefinición de la situación, suele ser la prueba fehaciente de la aleatoriedad del riesgo y de que "ahora todo ha cambiado". En segundo

14 R. Agnew (1985) ha detectado técnicas de neutralización, es decir, formas de argumentación para disminuir la disonancia cognitiva que produciría ser víctima de un crimen. Se tendería así a minimizar el daño sufrido ("no me pasó nada"), a transformarlo en una experiencia de aprendizaje futuro ("ahora sé como manejarme si me vuelve a pasar") o hasta la autoadjudicación de responsabilidad ("debería haber sido más cuidadoso"). 
lugar, cuando los casos se reiteran, se produce una suerte de aprendizaje de cómo atravesar el momento, atenuar el temor y disminuir el riesgo. Así, entre jóvenes que han experimentado robos durante sus procesos de socialización; tales experiencias, en lugar de alimentar una tendencia al encierro, generaba más confianza en el uso autónomo del espacio público. En fin, en cuanto a las actitudes punitivas, si bien los relatos previos son los que dan sentido a la experiencia, en algunas situaciones se detectaban luego de uno o más robos algunos desplazamientos punitivos, como afirmaba una mujer de 35 años, enmarcada en un relato de "inseguridad jurídica" quien nos confesaba que a la tercera vez que le robaron la cartera le "agarró unas ganas de hacer justicia yo misma" a pesar de apresurarse a decir en seguida "pero yo sé que eso está mal y no se debe".

La última paradoja concierne la edad: los jóvenes aparecen como los más victimizados y los menos temerosos. En la encuesta del 2007 en la ciudad de Buenos Aires, los jóvenes de 15 a 19 años de la zona sur, donde las tasas de delito son más elevadas, expresaban valores cercanos del promedio de sus barrios. Todo sucede como si esa actitud de valoración del riesgo que tradicionalmente se utilizó para explicar el menor temor juvenil ya no estuviera tan presente en distintos estratos sociales. En parte se debe a la alta tematización en las familias, las escuelas y los medios de los riesgos y de la inseguridad y es probable que así como la inseguridad definida como problema social ha legitimado la expresión de temor en los adultos varones, también la haya vuelto más legítima entre los jóvenes. En suma, la extensión de la preocupación y el recurso al abordaje cualitativo nos permitió revisar paradojas de la inseguridad cinceladas en los países centrales donde la inquietud era más restringida. Distancias sociales y geográficas diferentes según las clases; una legitimidad de expresar el temor en adultos varones y en jóvenes a partir de la redefinición de la situación y un mayor peso de la victimización en la expectativa de sufrir otro delito y en deslizamientos punitivos, conforman las particularidades del caso argentino y, quizás de otros países de la región.

\section{LA GESTIÓN DE LA INSEGURIDAD}

La "gestión de la inseguridad" son las acciones defensivas y elusivas, la incorporación de dispositivos y la adscripción a servicios cuyo objetivo común es lograr una sensación de control sobre las amenazas percibidas, intentando un equilibrio entre las precauciones y el mantenimiento de las rutinas habituales. La forma concreta de tal gestión será el resultado de dos factores: una evaluación del peligro del entorno - que determinará cuáles son las partes del mundo circundante que deben ser aseguradas - y la posibilidad diferencial de acceso a los dispositivos. En cuanto a lo primero, los casos podrían ubicarse en un continuo: en un extremo hay una evaluación de peligrosidad total, como en la alterofobia, que restringe los espacios transitados y exige la máxima vigilancia posible; en el otro prima un juicio de seguridad o neutralidad de riesgos "por defecto", y son entonces puntuales los sitios u horarios a evitar o sobre los que debe concentrarse el control ${ }^{15}$. El segundo factor depende del grado de posibilidad de acceder a dispositivos técnicos, de frecuentar espacios controlados y de delegar en terceros la gestión de los ámbitos que se desea asegurar.

En gran medida para satisfacer y retroalimentar estas demandas, el mercado de seguridad privada y electrónica ha conocido un gran desarrollo en los últimos años ${ }^{16}$, pero no debe inferirse que siempre es resultado del temor individual. Algunos forman parte de la oferta de un determinado servicio: hay cámaras de vigilancia y guardias las 24 horas en casi toda la oferta de nuevos apartamentos para sectores medios-altos o la seguridad privada ya está instalada en la calle donde alguien se muda. También su validez para disminuir la victimización no es uniforme: hemos demostrado en el caso de Buenos Aires que en los barrios con menor seguridad pública, no tienen un efecto significativo, por el contrario, en las zonas donde se asocian con una mayor presencia policial, el efecto

\footnotetext{
15 Esta idea se ha inspirado en el análisis de Ruth Simpson (1996), quien afirma que el mundo y la caracterización de lo riesgoso se percibe a partir de tres marcos: uno más cauto, que supone que todo es peligroso hasta que se demuestre lo contrario; uno confiado, que en oposición considera que el contexto es seguro y sólo algunos elementos son peligrosos, y un marco neutro, que no tiene juicio previo.

16 En el caso de la seguridad privada F. L. Valcarce (2008) estima la existencia de 1200 empresas de seguridad privada que emplean alrededor de 120000 personas, cuya gravitación se advierte al considerar que el total de fuerzas policiales en el país comprende alrededor de 230000 efectivos.
} 
de resguardo se produce (BERGMAN \& KESSLER, 2009). Sean cuales fueren los motivos de la adquisición y su eficacia, las acciones y dispositivos operarán sobre el sentimiento de inseguridad: a veces aplacarán el desasosiego, otras lo intensificarán y en ocasiones funcionan como un recordatorio constante de una aparente amenaza circundante.

Un primer interrogante entonces es si los dispositivos y acciones disminuyen o no el propio temor. Coincidimos con Bruno Latour (2007) en que los objetos desempeñan una función central para estabilizar relaciones sociales por definición fluctuantes. Una alarma, guardias privados en casas, restaurantes o colegios privados, luces fotoeléctricas, un taxi que espera hasta que el pasajero entre a su casa posibilitan delegar en un tercero, en objetos o en personas, parte de la gestión de la inseguridad. Estos elementos están mucho más presentes en sectores medios y altos que en los populares. Los dispositivos contribuyen a lograr una mayor sensación de seguridad cuando pueden ser incorporados en la vida cotidiana, en las acciones más habituales y naturalizadas: salir a cenar y dejar la alarma conectada ayuda a no tener presente todo el tiempo que la casa "está sola". Por el contrario, cuando los implementos tienen una extrema presencia, incrementan el temor o, por lo menos, recuerdan en forma constante la existencia de peligros, como observábamos en los barrios privados, donde los dispositivos de vigilancia, guardias, cercos y otro tipo de controles, hacían las veces de un recordatorio de las amenazas circundantes. Algo similar sucede cuando las acciones defensivas adoptadas dependen sobre todo de gestos y acciones llevadas a cabo con el propio cuerpo: "cuando llego a casa con el auto, llamó antes de llegar, doy una vuelta a la manzana antes de bajar y toco la bocina dos veces para avisar que está todo tranquilo" era el ritual cotidiano de un comerciante de una periferia de Buenos Aires.

Pero más allá del efecto en sus propietarios, los dispositivos pueden actuar como signos en aquel que los observa. En la vida cotidiana, afirma D. Norman (1993) hay "objetos cognitivos" que funcionan de recordatorio, asociados con pensamientos o representaciones del mundo. La profusión de dispositivos de seguridad en una zona suele hacer pensar a quien los mira que se encuentra en un lugar inseguro. "Algo estará pasando con la inseguridad, porque antes no veía tantas rejas por el barrio y ahora si" reflexionaba una ama de casa de Posadas, Misiones. La inseguridad se leía a partir de cambios observados en el ambiente. El sentimiento de inseguridad tiene un aspecto comparativo respecto del pasado, aunque la forma de la periodización no es única. En cuanto diagnóstico de un estado de la sociedad, se construye en oposición dicotómica con un tiempo pretérito visualizado tranquilo. Pero al indagar sobre los cambios personales por la nueva situación, los hitos de referencia eran las transformaciones paulatinas en el uso de la ciudad, aquellos lugares que se dejaron de frecuentar, que formas de recorridos urbanos se realizaban antes y ahora: "en la época de Menem dejé de ir de noche, ahora ya no paso ni de día" nos contaba en Córdoba un obrero respecto de un barrio considerado ahora por él como muy peligroso, revelando la relación existente entre sentimiento de inseguridad y cambios en la experiencia urbana.

En fin, la gestión de la inseguridad afecta también las actividades comerciales pero de forma diferencial según la clase. Comerciantes y conductores de autos de alquiler de barrios populares narraban distintas estrategias para poder evaluar el riesgo de cada presunto cliente. "Yo siempre le doy charla al pasajero" contaba un remisero de la periferia de Buenos Aires "si no me responde, es posible que en realidad me quiera robar y por las dudas le digo que el auto dejó de funcionar y vuelvo a la agencia". De la simple confianza generalizada suficiente para una transacción, como señalaba G. Simmel (2002), la inseguridad complejiza la situación, requiriéndose información adicional para llevar a cabo el intercambio. En comerciantes de sectores mediosaltos suele haber un conocimiento detallado todo tipo de dispositivos electrónicos. No obstante, ninguna alarma, por más sofisticada que fuera, parecía ser suficiente: en sus relatos todo sucedía como si el delito estuviera siempre en la delantera en cuanto burlar los recaudos tecnológicos más novedosos. A nuestro entender, más que una aporía técnica, la desazón de estos "clientes insatisfechos" era la cabal demostración de que la seguridad es un bien colectivo y que ningún servicio privado, ningún dispositivo, más allá de sus promesas, puede reemplazar su provisión pública.

\section{REFLEXIONES FINALES}

A la vez de repasar diferentes consecuencias de la extensión del sentimiento de inseguridad en el caso argentino, este artículo intenta contribuir 
a la comparación con estudios similares en otros países latinoamericanos. No sucede, claro está, lo mismo en los distintos centros urbanos; en algunas naciones la extensión de la inseguridad ya tiene una larga data: mercados, relatos y acciones que en el caso analizado resultan en pleno proceso, estarán más afianzados o habrán cobrado nuevas características mientras que otros lugares, recién pueden estar comenzando. Concluimos este trabajo, entonces, señalando aquello que puede acercar y diferenciar el caso argentino de otros comparables.

Habrá en cada país una definición nativa de inseguridad. En los centros urbanos argentinos se construía en torno a la aleatoriedad de la amenaza ligado a un delito percibido como desorganizado. Tal aleatoriedad retroalimentaba la extensión del temor pero al mismo tiempo contribuía a no fijar la detracción general contra un grupo determinado. ¿Se trata de un rasgo compartido o allí donde el crimen organizado, en particular el narcotráfico; está presente en las percepciones públicas, otra será la definición de inseguridad y sus consecuencias? Es dable suponer que cuando más se focalice en alteridades definidas, consideradas amenazantes, más discursos punitivos y mayor tolerancia frente a acciones represivas contra los mismos se observen.

En cuanto a los relatos, el trabajo por dotar de sentido y orientar las acciones estará sin dudas presente en otras latitudes, también la posibilidad de agruparlos en los tres grupos elegidos, según la intensidad de la preocupación. El eje central del relato argentino más difundido es la cuestión social, dado que el delito ha aumentado en concomitancia con el incremento de la pobreza, la desigualdad y el desempleo en los años 1990. La cuestión social atenúa en gran medida las actitudes punitivas, en cuanto hace reposar sobre la estructura parte de las causas del problema. Pocas dudas caben que la cuestión social estará presente en los relatos de diferentes países, lo que podría variar es el peso o su asociación con otros factores, como el crimen organizado, por lo cual también la su efecto atenuante cambiaría. Otros relatos presentados tendrán más fácilmente su correlato, las lecturas de cuño moral o las que propugnan un encierro defensivo, mientras que aquellos vinculados con la historia y las narrativas nacionales así como con los grupos sobre los que converge el temor $\mathrm{y} / \mathrm{o}$ los prejuicios de cada sociedad, revelaran más diferencias.

Son esperables concordancias en las paradojas de la inseguridad pues están vinculadas a procesos socioculturales y espaciales comunes a varios países de la región. Distanciamiento y proximidad se asocian con formas de disposición espacial de los grupos sociales habitual en las grandes urbes; la mayor legitimidad del temor en adultos varones y en jóvenes son indisociable de una presumible morigeración de los estereotipo de género y una definición de la inseguridad como problema público. En cuanto a la gestión de la inseguridad, habrá diferencias importantes, pero en casi toda la región hay un desarrollo tal de la seguridad electrónica y sobre todo de la seguridad privada, que el mismo monopolio de la fuerza legítima por parte del Estado está desafiado.

Finalmente, resta la cuestión política. Para el caso argentino postulamos la existencia de tres grupos, en lugar de una dicotomía entre democráticos y punitivos y sostuvimos que la suerte futura del tema se juega en lo que suceda con el grupo intermedio, pasible de deslizamientos punitivos. Si toda construcción política es contingente, lo cierto es que la historia reciente en nuestra región y en los países centrales no nos autoriza a ser muy optimistas sobre los cambios políticos que la extensión de la inquietud acarrea. Pero lo que suceda dependerá no tanto de la evolución de las tasas de delito como de las respuestas que el poder político, la academia y los medios de comunicación puedan dar; de las forma en que la vida urbana se reconfigure y de las imágenes y juicios sobre distintos grupos que en el espacio público se acepten. Y si bien a lo largo del trabajo nos distanciamos de quienes postulaban una relación necesaria entre temor y autoritarismo, no por ello dejamos de creer que parte de la calidad futura de nuestras democracias se juega en las respuestas que las sociedades latinoamericanas sean capaces de dar a los interrogantes que la extensión de la inseguridad hoy les plantea.

Gabriel Kessler (gabriel_kessler@yahoo.com.ar) é Doutor em Sociologia pela École des Hautes Études en Sciences Sociales (EHESS, França) e pesquisador do Consejo Nacional de Investigaciones Científicas y Técnicas (Conicet) e da Universidad Nacional de La Plata (UNLP, Argentina). 


\section{REFERÊNCIAS BIBLIOGRÁFICAS}

AGNEW, R. 1985. Neutralizing the Impact of Crime. Criminal and Justice Behaviour, London, v. 12, n. 2, p. 221-239, June.

BERGMAN, M. \& FLOM, H. 2008. Policía y comunidad: una comparación entre fuerzas policiales del Distrito Federal y el Estado de México y la Ciudad Autónoma de Buenos Aires. Documento de trabajo n. 21. Ciudad de México: Centro de Investigación y Docencia Económica.

BERGMAN, M. \& KESSLER, G. 2009. Vulnerabilidad al delito y sentimiento de inseguridad en Buenos Aires. Desarrollo Económico, Buenos Aires, v. 48, n. 190-191, p. 209-234.

CALDEIRA, T. P. R. 2001. City of Walls. Crime, Segregation and Citizenship in São Paulo. Berkeley: University of California.

CASTEL, R. 2003. L'Insécurité sociale: qu'estce qu'être protégé? Paris: Seuil.

CHINCILLA, L. 2009. Mi propuesta de seguridad ciudadana. La Nación, San José, 12.nov. Disponível em: http://wvw.nacion.com/ln_ee/ 2009/noviembre/12/opinion2156680.html. Acesso em: 15.set.2011.

DAMMERT, L.; ALDA, E. \& RUIZ, F. 2008. Desafios de la seguridad ciudadana en Iberoamérica. Santiago de Chile: Facultad Latino-Americana de Ciencias Sociales. Disponível em: http://www.securitytransformation. org/images/documentos/338 analisislatino america.pdf. Acesso em: 15.set.2011.

DAMMERT, L. \& ARIAS, P. 2007. La construcción de una sociedad temerosa: crimen y castigo en Chile. In: ISLA, A. (comp.). En los márgenes de la ley. Inseguridad y violencia en el Cono Sur. Buenos Aires: Paidós.

DE CERTEAU, M. 2000. La invención de lo cotidiano. V. I: Artes del hacer. Ciudad de México: Universidad Iberoamericana.

DEMAZIÈRE, D. \& DUBAR, C. 1997. Analyzer les entretiens biographiques. L'exemple de récits d'insertion. Paris: Nathan.

DITTON, J. \& FARRALL, S. (ed.). 2000. The Fear of Crime. London: Ashgate.
FERRARO, K. 1995. Fear of Crime. New York: University of New York.

1996. Women's Fear of Victimization: Shadow of Sexual Assault? Social Forces, Chapell Hill, v. 75, n. 2, p. 667-690, Dec.

FERRARO, K. \& LAGRANGE, R. 1987. The Measurement of Fear of Crime. Sociological Inquiry, Malden, v. 57, n. 1, p. 70-101, Jan.

GARLAND, D. 2005. La cultura del control. Crimen y orden social en la sociedad contemporánea. Barcelona: Gedisa.

GIDDENS, A. 1991. Modernidad e identidad del yo. Madrid: Península.

HALE, C. 1996. Fear of Crime: A Review of the Literature. International Review of Victimology, Sheffield, v. 4, n. 2, p. 79-150.

HUME, D. 2002. Tratado de la naturaleza huma$n a$. V. II. Buenos Aires: Eudeba.

JACKSON, J. 2005. Validating New Measures of the Fear of Crime. International Journal of Social Research Methodology, London, v. 8, n. 4 , p. 297-315.

KARP, A. 2009. Surplus Arms in South America: A Survey. Geneva: Graduate Institute of International and Development Studies. Disponível em: http://www.humansecurity gateway.com/documents/SAS_SurplusArms SouthAmerica_Survey.pdf. Acesso em: 15.set.2011.

KESSLER, G. 2009. El sentimiento de inseguridad. Sociología del temor al delito. Buenos Aires: Siglo XXI.

KOONINGS, K. \& KRUIJT, D. 1999. Societes of Fear. The Legacy of Civil War, Violence and Terror in Latin America. New York: Zed.

KOSOVSKY, D. 2007. Delito y análisis de la información en Argentina. In: KAMINSKY, G.; KOSOVSKY, D. \& KESSLER, G. (orgs.). El delito en la Argentina poscrisis. Aportes para la comprensión de las estadísticas públicas y el desarrollo institucional. Buenos Aires: Friedrich Ebert Stiftung.

LAGRANGE, H. 2003. Demandes de sécurité. France, Europe, États-Unis. Paris: Seuil. 
LATINOBARÓMETRO. 2008. Informe anual 2008. Santiago de Chile: Corporación Latinobarómetro. Disponível em: http:// www.jdsystems.es/latinobarometro/ LATBD_Latinobarometro_Informe_2008.pdf. Acesso em: 15.set.2011.

LATOUR, B. 2007. Changer de société, refaire de la Sociologie. Paris: La Decouverte.

LECHNER, N. 1990. Los patios interiores de la democracia. Subjetividad y política. Ciudad de México: Fondo de Cultura Económica.

LIANOS, M. \& DOUGLAS, M. 2000. Dangerization at the End of Deviance: The Institutional Environment. In: GARLAND, D. \& SPARKS, R. (eds.). Criminology and Social Theory. Oxford: Oxford University.

NINO, C. 1992. Un país al margen de la ley. Buenos Aires: Emecé.

NORMAN, D. 1993. Les artefacts cognitifs. In: CONCIN, B.; DODIER, N. \& THÉVENOT, L. (dirs.). Los objets dans l'action. De la maison au laboratoire. Paris: Ecole Pratique des Hautes Etudes en Sciences Sociales.

OTAMENDI, A. 2009. Interpretaciones sobre seguridad ciudadana y sobre el rol del Estado de los argentinos. Artículo presentado en el Congreso de la Latin American Studies Association, ocurrido en Río de Janeiro, el 1114 de junio. Disponível em: http:// www.resdal.org/experiencias/lasa2009-paperotamendi.pdf. Acesso em: 15.set.2011.

REGUILLO, R. 2000. La construcción social del miedo. Narrativas y prácticas urbanas. In: ROTKER, S. (comp.). Ciudadanías del miedo. Caracas: Rutgers.

ROBERT, P. \& POTTIER, M.-L. 1997. « On ne sent plus en securité ». Délinquance et insécurité. Une enquête sur deux décennies. Revue Française de Science Politique, Paris, v. 47, n. 6, p. 707-740.

2004. Les préocupations sécuritaires: une mutation? Revue Française de Sociologie, Paris, v. 45, n. 2, p. 211-242.

ROCHÉ, S. 1998. Expliquer le sentiment d'insécurité: pression, exposition, vulnérabilité et acceptabilité. Revue Française de Science Politique, Paris, v. 48, n. 2, p. 274-305.
SACCO, V. 1990. Gender, Fear and Victimization: A Preliminary Application of Power-Control Theory. Sociological Spectrum, Atlanta, v. 10, n. 4 , p. 485-506.

SACCO, V. \& GLACKMAN, W. 1987. Vulnerability, Locus of Control and Worry about Crime. Canadian Journal of Community Mental Health, v. 6, n. 1, p. 99-111.

SIMMEL, G. 2002. Sociología. Madrid: Alianza.

SIMPSON, R. 1996. Neither Clear Nor Present: The Social Construction of Safety and Danger. Sociological Forum, v. 11, n. 3, p. 549-562.

SLUCKIN, W. (ed.). 1979. Fear in Animals and Men. New York: Van Rostand Reinhold.

STAFFORD, M. \& GALLE, O. R. 1984 Victimization Rates, Exposure to Risk, and Fear of Crime. Criminology, Malden, v. 22, n. 2, p. 173-185.

TUDELA, P. 2006. Naturaleza y magnitud de los problemas de violencia delictual e inseguridad en América Latina y el Caribe. Santiago de Chile: Centro de Investigación y Desarrollo Policial.

VALCARCE, F. L. 2008. La Marchandisation de la securité privée. Une remise en cause des «fonctions régaliennes» de l'Etat? Nouvelle Revue Argentine, Paris, n. 2, p. 41-52. Disponível em: http://www.lanouvellerevueargentine. com/assets/files/article $\% 20$ Valcarce $\% 20 \%$ 20p\%2041-52.pdf. Acesso em: 15.set.2011.

VAN DIJK, J.; MANCHEN, R.; VAN KESTEREN, J. \& HIDEG, G. 2005. Burden Of Crime in the EU: A Comparative Analysis Of The European Crime And Safety Survey 2005. Brussels: European Crime and Safety Survey. Disponível em: http://www.gallupeurope.be/euics/Xz38/downloads/EUICS\%20$\% 20$ The $\% 20$ Burden $\% 20$ of $\% 20$ Crime $\%$ 20 in $\% 20$ the $\% 20$ EU.pdf. Acesso em: 15.set.2011.

WAISELFISZ, J. 2008. Mapa de la violencia: la juventud en América Latina. Brasília: Sangari.

WERTH, F. 2010. El nuevo gobierno y la seguridad. La Tercera, Santiago de Chile, 25.fev. Disponível em: http://www.latercera. com/contenido/895_228895_9.shtml. Acesso em: 15.set.2011. 


\section{OUTRAS FONTES}

Estudio AC Nielsen: la inestabilidad laboral y la 2006. Nuevo Digital, 15.feb. Disponível em: delincuencia desplazan a la economía el la lista de preocupaciones de los latinoamericanos.

http://www.nuevodigital.com/2006/02/15/ p3487. Acesso em: 15.set.2011. 
CONCERNS WITH SAFETY IN LATIN AMERICA: NARRATIVES, ACTIONS AND POLICIES FROM THE ARGENTINEAN CASE

\section{Gabriel Kessler}

Concern with crime has spread throughout Latin America. In addition to presenting the results of research carried out in Argentina using quantitative and qualitative methods, this article seeks to contribute to comparative work on similar processes in other countries of the region. Our central idea is that increasing feelings of lack of safety produce consequences at the level of the social imaginary - which we will refer to here as narratives of unsafeness - and, at the levels of social practice, management of such fears and concerns. This leads to a change in the exclusive association of fear and authoritarianism, forged at a time when lack of safety was a minority concern. The central paradoxes of this field of study in the Anglo-Saxon world, that is, the enigma of why those groups who are less subjected to crime are apparently the most fearful, are examined, in the light of the Argentinean case.

KEYWORDS: crime; fear; Argentina. 
L'EXTENSION DU SENTIMENT D'INSÉCURITÉ DANS L'AMÉRIQUE LATINE: DES RAPPORTS, DES ACTIONS ET DES POLITIQUES DANS LE CAS ARGENTIN

\section{Gabriel Kessler}

La préoccupation du délit s'est répandue partout en Amérique Latine. L'article présente les résultats d'une investigation réalisée en Argentine avec des méthodes quantitatives et qualificatives ; de plus, 
l'article essaie de contribuer à la comparaison avec des processus similaires dans d'autres pays de la région. L'idée centrale, c'est que la généralisation du sentiment d'insécurité produit des conséquences dans le plan imaginaire, ce qui s'appellera « des rapports de l'insécurité et des pratiques sociales, la gestion de l'insécurité ». Nous avons aussi le changement de l'association exclusive entre la crainte et l'autoritarisme, déguisées au moment où l'insécurité était une préoccupation d'une minorité. Il y a un grand nombre de paradoxes centraux dans ce domaine d'étude dans le monde anglo-saxon, c'est à dire, l'énigme de la raison pour laquelle les groupes les moins victimisés sont apparemment ceux qui craignent le plus, ce que nous analysons pour le cas argentin.

MOTS-CLÉS: le délit ; la crainte ; l’Argentine. 